\title{
LINGUOSEMIOTIC REALIZATION OF THE CONCEPT SHAPE SHIFTING IN THE ENGLISH FOLK CULTURE (BASED ON THE FOLK TALE DISCOURSE)
}

\author{
Olga A. Plakhova \\ Togliatti State University, Togliatti, Russia
}

\begin{abstract}
The research objective consists in the study of the linguosemiotic manifestation of the concept shape shifting in the English folk culture. The present work allows to identify the concept structure as a scenario frame whose structural minimum comprises the classifiers: the "subject of the shape shifting", "object of the shape shifting", "action" and "circumstances of the action". The temporal and causal classifiers as well as the "state of the shape shifting object" and "consequences of shape shifting" belong to the optional ones having irregular linguosemiotic actualization. The English folk tale discourse demonstrates the diversity of the linguosemiotic manifestation of the concept represented by items of a wide range of codes (zoomorphic, ornithomorphic, amphibiomorphic, reptilemorphic, somatic, artifact, mineral, coloromorphic, temporal, numerological, esoteric, manipulative, etc.). The article confirms the idea that the original and the transformed shapes of the objects of shape shifting are opposed in the English folk tale discourse as "alive - dead", "beautiful - ugly", "sublime terrible". In its complete form the concept shape shifting can be revealed within one folk text more than once. All the elements of the structural-meaningful minimum are proved to remain constant; only the intention of the subject of the shape shifting becomes variable. Accordingly it concerns either casting a spell on, or taking a spell off, or punishing for doing the evil (shape shifting as retribution). The paper contains the examples of a discursive link between the first two shape shifting motifs (enchantment - disenchantment) manifested by the conditions of regaining the original shape.

Key words: discourse, folk tale discourse, folklore, concept, frame, linguosemiotics, shape shifting.

Citation. Plakhova O.A. Linguosemiotic Realization of the Concept Shape Shifting in the English Folk Culture (Based on the Folk Tale Discourse). Vestnik Volgogradskogo gosudarstvennogo universiteta. Seriya 2. Yazykoznanie [Science Journal of Volgograd State University. Linguistics], 2021, vol. 20, no. 6, pp. 99-110. (in Russian). DOI: https://doi.org/10.15688/jvolsu2.2021.6.9
\end{abstract}

\section{ЛИНГВОСЕМИОТИЧЕСКОЕ ВОПЛОЩЕНИЕ КОНЦЕПТА «SНAPE SHIFTING / ОБОРОТНИЧЕСТВО» В АНГЛИЙСКОЙ НАРОДНОЙ КУЛЬТУРЕ (НА МАТЕРИАЛЕ СКАЗОЧНОГО ДИСКУРСА)}

\author{
Ольга Александровна Плахова
}

Аннотация. Цель исследования состоит в описании лингвосемиотического представления концепта «shape shifting / оборотничество» в английской традиционной культуре. Установлено, что концепт имеет вид сценарного фрейма, в структурный минимум которого входят классификаторы «субъект», «объект», «действие» и «обстоятельства действия». Все элементы структурно-содержательного минимума остаются постоянными. Переменной величиной становится только интенция субъекта оборотничества, в соответствии с 
которой возможно наложение заклятия (заколдовывание), снятие заклятия (расколдовывание) и кара за содеянное зло (оборотничество как воздаяние). Периферийные когнитивные признаки классификатора «объект» осуществляют связь исследуемого концепта с другими концептами группы «изменение внешнего облика». Особое внимание уделено дискурсивной связи двух мотивов оборотничества (заколдовывание - расколдовывание), которая осуществляется за счет вербализации когнитивного признака «условия возвращения исходного облика». Результаты анализа языкового материала свидетельствуют о том, что лингвосемиотическая манифестация концепта разнообразна и отличается широкой номенклатурой единиц зооморфного, орнитоморфного, амфибиоморфного, рептилеморфного, инсектоморфного, соматического, артефактного, минерального, колороморфного, темпорального, нумерологического, эзотерического, манипулятивного, акционального и других кодов. Противопоставление исходного и трансформированного обликов объектов оборотничества реализуется в англоязычном сказочном дискурсе в оппозициях «живой - мертвый», «прекрасное - безобразное», «возвышенное - ужасное».

Ключевые слова: дискурс, сказочный дискурс, фольклор, концепт, фрейм, лингвосемиотика, оборотничество.

Цитирование. Плахова О. А. Лингвосемиотическое воплощение концепта «shape shifting / оборотничество» в английской народной культуре (на материале сказочного дискурса) // Вестник Волгоградского государственного университета. Серия 2, Языкознание. - 2021. - Т. 20, № 6. - C. 99-110. - DOI: https://doi.org/ 10.15688/jvolsu2.2021.6.9

\section{Введение}

Оборотничество как явление магической смены облика уходит своими корнями в тотемические и анимистические верования. В исследованиях тотемических мифов выделяют связанные с разным устройством архаического общества (матриархат и патриархат) сюжеты, в которых заключается брак человека с тотемом. При этом маркером «чужой» отмечен либо жених героини (матрилинейный счет родства), либо невеста героя (отцовское право) [Решетникова, 2006, с. 120]. Животныетотемы воспринимались в древности как прародители, как проводники, ведущие человека в сложных ситуациях жизни, как некие константы бытия и глубокие образы, наделенные определенным набором качеств, которые со временем укоренились в коллективном бессознательном в виде архетипов [Жарова, 2014; Калинин, 2015; Киндря, 2010; Хазанкович, 2009].

Оборотни устойчиво связываются в народном сознании с потусторонним миром. Соответственно, оборотничество маркируется как хаотическое и демоническое, противопоставляясь упорядоченности и правильности реального мира [Неклюдов, 1979; 1998]. Подобное противопоставление выражается в культуре в оппозициях «высокое- низкое», «свое-чужое», «истинное - преображенное», «живое - мертвое», «одушевленное - неодушевленное», «видимое невидимое», «красивый - уродливый», «добрый - злой» [Кузьмин, 2009]. Эту же точку зре- ния разделяет А.П. Решетникова, указывая на генетическую корреляцию дефектности хтонических существ и половинчатости оборотнейтотемов [Решетникова, 2006, с. 122].

Мотив смены человеческого облика на зооморфный / орнитоморфный обладает глубоким смыслом для человеческой культуры в целом и находит отражение не только в фольклорном, но и в художественном дискурсе [Королькова, 2013; Любимова, 2016; Тиманова, 2008; Хазанкович, 2009].

Феномен изменения внешнего облика героя исключительно многообразен в народной культуре, что приводит к сложностям в определении объема понятия «оборотничество». С одной стороны, оборотничество приравнивается к превращению, поскольку последнее представляет собой переход одной материи в другую [Коломакина, 2012; 2017 ]. С другой стороны, оборотничество, предполагающее слияние, вытеснение и подмену сущностей, практически исключается из мифопоэтической картины мира. Вместо него, как считает Н.А. Киндря, исследователь в большинстве случаев имеет дело с оборачиванием, будь то трансформация Иванушки-дурачка в Ивана-царя или царевича в Ясного сокола [Киндря, 2009, с. 174175]. Кроме того, оборотничество рассматривается как одна из форм изменения внешнего облика, наряду с маскарадом, наготой, обнажением, заголением и т. д. [Краюшкина, 2008, с. 73]. 
В народной культуре трансформация облика является одним из результатов магического воздействия сказочного персонажа [Acтафурова, Плахова, 2013, с. 121]. Вместе с тем способность к смене личины разнится не только у мифологических персонажей разных групп, но и у существ, объединенных фольклорным сознанием в один концепт. В частности, изучение англоязычного сказочного дискурса свидетельствует о том, что данным признаком обладают мифологические персонажи, формирующие ядро соответствующего концепта - фейри или великаны. Персонажи, занимающие периферийные области, данного свойства уже лишаются, компенсируя его отсутствие социально значимыми признаками [Плахова, 2011а; 2011б; 2011в; Плахова, Астафурова, 2011].

Исходя из разного понимания сущности оборотничества, авторы предлагают разные принципы классификации явления. Оборотничество может быть высоким (восходящим к тотемизму), низким или относиться к нашему миру. По цели выделяются возрастное оборотничество, принятие облика другого ролевого плана, изменение сущности. Кроме того, оборотничество классифицируется как временное, сознательное и несознательное, полное и частичное, добровольное и насильственное, а также субъектно-субъектное и субъектно-объектное [Коломакина, 2012, с. 20; Коломакина, 2017, c. 35; Краюшкина, 2008, с. 73-75].

Актуальность избранной темы связана с недостаточной изученностью значимого для исследуемой лингвокультуры концепта «shape shifting / оборотничество» в лингвосемиотическом и когнитивном аспектах, его структурно-содержательного минимума и связи с другими мифологическими концептами.

Новизна предлагаемого вниманию читателя исследования состоит в изучении особенностей лингвосемиотического представления концепта «shape shifting / оборотничество» в англоязычном сказочном дискурсе и описании его структурно-семантических характеристик.

Понимание оборотничества в настоящей работе базируется на семантике ключевой номинации соответствующего концепта в английской лингвокультуре. Первый элемент лексемы shape shifting получает в словаре следующее толкование: shape - 1 . The outer form of something (выделено нами. - О. П.), by which it can be seen (or felt) to be different from something else (LDELC, 2000, p. 1236) / Внешний облик, по которому что-либо воспринимается как другое, отличается от других (здесь и далее перевод с английского наш. $O$. П.). Данное значение полностью передает сущность оборотничества как полную смену формы кого-либо (чего-либо). Соответственно, к оборотничеству мы относим широкий спектр явлений, включая трансформации животных-тотемов, традиционную для волшебных сказок добровольную и насильственную смену антропоморфного облика на любой другой (зооморфный, орнитоморфный, флороморфный, артефактный и т. д.), а также чары (glamour), посредством которых мифологические существа заставляют человека воспринимать окружающие объекты в искаженном виде. Более подробно данный вид гипнотического воздействия был описан в [Плахова, 2012]. Переходными между оборотничеством и иными формами изменения внешнего облика являются частичная трансформация внешности персонажа в результате увечий и сокрытие героиней своего истинного облика посредством переодевания в одежду из растений, шкур животных или перьев птиц.

\section{Материал и методы}

Целью данной работы является дескрипция специфики лингвосемиотической манифестации концепта «shape shifting / оборотничество» в английской народной культуре.

Гипотеза настоящего исследования состоит в том, что в структурном отношении концепт «shape shifting / оборотничество» представляет собой сценарный фрейм, состоящий из постоянных и переменных величин. Входящие в структурный минимум концепта когнитивные признаки осуществляют его связь с другими концептами, аккумулирующими в народном сознании представления о смене внешнего облика. Мы предполагаем, что данный концепт фиксируется в англоязычном сказочном дискурсе посредством лингвосемиотических единиц разных групп, организованных в оппозиции категории «чудесное». 
В качестве материала исследования были использованы тексты разных жанров, составляющие англоязычный сказочный дискурс (классические волшебные сказки, предания, легенды). Исследуемый корпус составили 124 текста, входящие в три сборника английских сказок общим объемом 635 страниц.

В структурном отношении концепт «shape shifting / оборотничество» является сценарным фреймом и входит в народном сознании в качестве элемента в структуру большинства мифологических концептов («barguest / баргест», «boggle / боггл», «bogie / боуги», «giant / великан», «water spirits / водные духи», «goblin / гоблин», «dragon / дракон», «devil / дьявол», «people with magic ability / люди, обладающие магическими способностями», «mermaid / pyсалка», «fairy / фейри», «hobgoblin / хобгоблин»), в том числе во многих случаях в структурно-содержательный минимум концепта [Плахова, 2013].

\section{Результаты и обсуждение}

\section{Структурно-содержательный минимум концепта «shape shifting / оборотничество»}

Будучи концептом сценарного типа, «shape shifting / оборотничество» содержит в своей структуре информацию о том, как данный процесс разворачивается во времени. Обязательными классификаторами фрейма концепта являются «субъект оборотничества», «объект оборотничества», «действие» и «обстоятельства действия». Рассмотрим, какие лингвосемиотические средства используются для их репрезентации в сказочном дискурсе.

Субъект оборотничества. Субъектом оборотничества традиционно выступают мифологические персонажи (the Red Ettin; Splug; the wicked dwarf; barguest; boggle; bogie; giant; goblin; dragon; devil; mermaid; fairy; hobgoblin, etc. / Рыжий Эттин; Сплаг; злой гном баргест; боггл; боуги; великан; гоблин; дракон; дьявол; русалка; фейри; хобгоблин), животные-тотемы (a husband that she never $s a w$; bird, etc. / муж, которого она никогда не видела; птица и т. д.), маги и колдуньи как транзитивные персонажи между реальным и потусторонним мирами (conjurer; wicked witch woman; the Witch Queen; hen-wife; witch; wizard, etc. / волшебник; злая ведьма; королева-ведьма; птичница; ведьма; волшебник и т. д.) и даже герои профанного мира (a beautiful maiden; Childe Wynd; queen; Kate Crackernut, etc. / прекрасная дева; Чайлд Уинд; королева; Кейт-Щелкунчик и т. д.). Средствами их репрезентации являются знаки-антропонимы и знаки-мифонимы, как нарицательные, так и собственные.

Объект оборотничества. Объект оборотничества всегда представлен в двух формах - исходной (первоначальной) и конечной (трансформированной). В случае насильственного оборотничества его объектом выступают, как правило, герои-люди. Их исходный облик манифестируется антропонимами, указывающими на их гендерную принадлежность и социальный статус, в сочетании с квалитативами: knights and ladies; a duke's daughter; prince; a beauteous maiden; his sister Margaret; the Queen of the Golden Mountain; Coo-my-dove; Tamlane; many beautiful ladies and valiant knights; a bonny girl; a handsome young prince / рыцари и дамы; дочь герцога; принц; прекрасная дева; его сестра Маргарет; королева Золотой Горы; Воркуюший Голубь; Тэмлейн; много прекрасных дам и доблестных рыцарей; красивая девушка; красивый молодой принц.

Трансформированный образ передается в сказочном дискурсе посредством широкой номенклатуры знаков зооморфного, орнитоморфного, амфибиоморфного и других кодов, обозначающих живых существ (hind; dove; bird; a sheep's head; a Laidly Worm; snake; adder; all sorts of birds and beasts; fishes and insects; frog; goshawk; heron; cygnet; swan / лань; голубь; птица; овечья голова; Уродливый Змей; змея; гадюка; разные птицы и звери; рыбы и насекомые; лягушка; ястребтетеревятник; цапля; лебеденок; лебедь), знаков артефактного (a red-hot glaive / меч, раскаленный докрасна), метеорологического (frozen ice; a huge flame of roaring fire / замерзший лед; ревущее огненное пламя) и минерального (a pillar of stone; stones / каменная колонна; камни) кодов, которые могут сопровождаться единицами колороморфного и нумерологического кодов (a white hind; 
twenty-four grey herons; seven cygnets / белая лань; двадцать четыре серые цапли; семь лебедят). В некоторых случаях в сказке используются вербальные знаки обобщенной семантики в сочетании с негативно маркированными квалитативами: shapes and forms; those frightful things; those unearthly monsters / формы и очертания; те ужасные существа; те таинственные чудовища.

Промежуточной ступенью между собственно оборотничеством и переодеванием являются ситуации приобретения персонажами увечий и неизлечимых заболеваний (a mangy face; leprosy; an ugly face; a squeaky voice; a lame leg; lameness / паршивое лицо; проказа; уродливое лицо; скрипучий голос; хромая нога; хромота) или переодевания в шкуры животных, одежду из тростника и оперений птиц (they made her a coat of catskin; the Catskin; the Rushen Coatie; and they took all the feathers and made a coat of them and gave it to her / они сшили ей одежду из кошачьей шкуры; Кошачья Шкура; Тростниковая Шапка; и взяли они все перья, и сшили из них плащ, и отдали его ей). В первом случае деформацию тела можно рассматривать как нарушение упорядоченности и возврат к бесформенности потустороннего мира; во втором случае внешний облик героини сохраняет реминисценции тотемических трансформаций. В этой связи когнитивные признаки «увечья» и «внешнее уподобление тотему» располагаются в периферийной области концепта «оборотничество», осуществляя его связь с другими концептами группы «изменение внешнего облика».

В отдельных случаях в ситуации расколдовывания объект оборотничества проходит несколько стадий смены облика, прежде чем предстанет в своем изначальном антропоморфном виде. Яркой иллюстрацией последовательной смены обличий может служить сказка «Tamlane»: the knight $\rightarrow$ frozen ice $\rightarrow$ a huge flame of roaring fire $\rightarrow$ an adder was skipping through her arms $\rightarrow$ a snake that reared up as if to bite her $\rightarrow$ a dove was struggling in her arms $\rightarrow$ a swan $\rightarrow$ a red-hot glaive $\rightarrow$ and this she cast into a well of water and then he turned back into a mother-naked man (Jacobs, 1894) / рыцарь $\rightarrow$ замерзший лед $\rightarrow$ ревущее огненное пламя $\rightarrow$ гадюка, вы- рывающаяся из ее рук $\rightarrow$ змея, готовая укусить ее $\rightarrow$ голубь, бьющийся в ее руках $\rightarrow$ лебедь $\rightarrow$ меч, раскаленный докрасна $\rightarrow$ она бросила его в колодец, и вышел он из него словно заново рожденный.

В ситуации добровольного оборотничества субъект и объект могут совпадать. Ими чаще выступают люди, обладающие магическими способностями, реже-мифологические персонажи. В результате трансформации они, как правило, теряют свой антропоморфный облик, что и находит отражение в единицах зооморфного кода (toad; cat; a suspiciously bright-eyed cat; a fierce old wehr-wolf; blackbird; hare; hound (greyhound); dog; the white doe; a black mare; a large black ox; owl; mouse; jackdaw / жаба; кошка; кошка со странными горящими глазами; свирепый старый волк-оборотень; черный дрозд; заяц; гончая; собака; белая лань; вороная кобылица; огромный черный бык; сова; мышь; галка).

Сосуществование в сказочном дискурсе исходного и трансформированного образов становится возможным благодаря эксплицитной манифестации элементов оппозиций «живой - мертвый» (and this she cast into a well of water and then he turned back into a mother-naked man; when his brother started into life - lay there entombed as if dead / она бросила его в колодец, и вышел он из него словно заново рожденный; когда его брат ожил - лежал там погребенный, словно мертвый), «прекрасное - безобразное» (a beauteous maiden; many beautiful ladies; a bonny girl; a handsome young prince; her own pretty head - a nasty frog; a Laidly Worm; the loathsome thing; a dreadful dragon; a huge ugly toad; a horrid wrinkled toad; a great ugly cat / прекрасная дева; много прекрасных дам; красивая девушка; красивый молодой принц; своей милой головкой отвратительная лягушка; Уродливый Змей; отвратительное существо; ужасный дракон; огромная отвратительная жаба; ужасная морщинистая жаба; огромная отвратительная кошка), а также правого члена оппозиции «возвышенное - ужасное» (those frightful things; those unearthly monsters / те ужасные существа; те таинственные чудовища).

В случае наложения чар на человека (glamour) наблюдается смысловой сдвиг оп- 
позиции «прекрасное - безобразное», поскольку искаженное восприятие объектов действительности, наоборот, маркируется лексемами с позитивными коннотациями в противоположность номинациям истинного облика. При этом в противопоставлении участвуют преимущественно знаки артефактного, с одной стороны, и натурморфного и соматического кодов, с другой стороны: the neat cottage - the large overhanging branches of an ancient oak; the fire place - hollow and moss-grown trunk; lamps - glow-worms; two older children - little flat-nosed imps; with many a grin and grimace were pulling the mothers ears with their long hairy paws / аккуратный дом - большие нависающие ветви старого дуба; камин - полый и покрытый лишайником ствол; лампы светляки; двое старших детей - маленькие плосконосые чертята; ухмыляясь и гримасничая, тянули мать за уши длинными мохнатыми лапами.

Действие. Когнитивный классификатор «действие» концепта «оборотничество» представлен в английской народной культуре знаками нескольких кодов. Важнейшую группу составляют эзотерические, акустические, манипулятивные и волюнтаристские акциональные знаки, которые в ситуации колдовства демонстрируют переход объекта оборотничества из одного качества в другое: transform into; turn into; change into; off falls her own pretty head, and on jumps a sheep's head; took a mallet and knocked him on the head; enchant; spell; cruel enchantment; bespell; it was this that had her forced to take on the dragon's shape; muttering over some burning herbs / трансформировать(ся) в; превратить(ся) в; превратить(ся) в; отвалилась ее собственная милая головка, а на ее месте появилась овечья голова; взял молоток и стункнул его по голове; очаровывать; накладывать заклятие; жестокое колдовство; накладывать заклятие; именно это прератило ее в дракона; бормочущая над горящими травами.

Процесс расколдовывания объекта актуализируется глагольными конструкциями с семантикой «освобождение от заклятия» (the enchantment broke; having broken his cruel enchantment; the spell was broken; unspell; when took the spell off him; release my sister from thy spells; she was disenchanted; free of the weirding of her father's wife / чары пали; разрушил жестокое колдовство; заклятие было разрушено; разрушить магическое заклинание; сняла с него заклятие; освободить мою сестру от заклятия; ее расколдовали; свободная от чар своей мачехи), конструкциями с семантикой «возвращение к жизни» (his brother started into life; raise my brothers to life; and they sprang at once into life / его брат ожил; вернуть моих братьев к жизни; и они ожили) и «возвращение исходного облика» (returned to their proper shapes; she be borrowed to her natural shape; and she was her own pretty self again / вернули свой изначальный облик; вернуть ей изначальный облик; вновь стала хорошенькой), акциональными и манипулятивными глаголами (young Tamlane had again been sained by the holy water and made Christian once more; he had only to touch with his wand; touched Anne three times with the wand; kiss; spring; seize; cling hold, etc. / молодой Тэмлейн был очищен святой водой и вновь стал христианином; ему нужно было всего лишь дотронуться палочкой; трижды коснулся Энн палочкой; поцеловать; прыгнуть; схватить; вцепиться и т. д.).

В сказочном тексте традиционно отсутствуют подробности принятия героем зооморфной личины. Трансформация происходит мгновенно, как, например, в «Earl Mar's Daughter»:

Suddenly Coo-my-dove changed into a goshawk and around him flew twenty-four grey herons and above them flew seven cygnets (Jacobs, 1890) / Внезапно превратился Воркующий Голубь в ястреба и улетел, окруженный двадцатью четырьмя серыми цаплями, и летели над ним семь лебедят.

Возвращение своего естественного антропоморфного облика получает более детальную дескрипцию за счет дополнительной актуализации знаков, отвечающих за чувственную сферу восприятия человека (аудитивных, тактильных, визуальных и др.). Приведем примеры из разных вариантов сказки «The Laidly Worm»:

The dragon's skin began to crack, then to peel away. First a human hand came out, then a shoulder, and then the flushed face of his sister, Margaret. The scaly skin fell to the ground, and there she stood, free of the weirding of her father's wife (Keding, Douglas, 2005, p. 73) / Кожа дракона начала трескаться и слезать. Сначала показалась рука, затем 
плечо, а затем и смущенное лицо его сестры Маргарет. Чешуйчатая шкура упала на землю, и она стояла, свободная от заклятия своей мачехи.

...And with a hiss and a roar the Laidly Worm reared back and before Childe Wynd stood his sister Margaret (Jacobs, 1890) / ...С шипением и ревом отпрянул Уродливый Змей, и перед Чайлд Уиндом стояла его сестра Маргарет.

Обстоятельства действия. Данный классификатор отражает несколько важных когнитивных признаков, однако не все из них получают одновременную лингвосемиотическую репрезентацию в англоязычном сказочном дискурсе.

Признак «инструменты и атрибуты превращения» представлен преимущественно артефактными, эзотерическими, натурмофными и нумерологическими знаками: mallet; spells; wand; green mantle; witchery; herbs; a twig of a rowan-tree; with spells three times three, and with passes nine times nine, etc. I молоток; заклинания; палочка; зеленая мантия; колдовство; травы; ветка рябины; заклинания три раза по три и пассами девять раз по девять и т. д. В сказке также манифестируются концептуальные признаки «обязательные условия оборотничества» (lifted the lid off the pot; to send the lassie to her next morning fasting / подняла крышку горшка; на следующее утро отправила девушку голодной) и «условия предотвращения оборотничества» (answer three questions; do as she wished / ответить на три вопроса; сделать так, как она пожелала).

Достаточно часто в обстоятельства оборотничества включаются и условия возвращения герою исходного облика посредством единиц акционального, вербального, аудиального, манипулятивного, эзотерического, нумерологического и других кодов (until a beautiful maiden of her own free will should do him a favor; some girl would do his bidding for a whole night, and chop off his head at the end of it; exercise all their magic on me; tried their spells on young Tamlane; give them no answer; let them do what they will, even if they beat and torment you; speak not a word, or you cannot save me, etc. / пока прекрасная дева по своей воли не окажет ему любезность; девушке придется выполнять его приказания в течение ночи и отрубить ему голову на рас- свете; опробовал на мне все свое магическое мастерство; наложила заклятие на молодого Тэмлейна; не отвечать; позволить им сделать все, что они хотят, даже если они будут бить и мучить тебя; молчи, или ты не сможешь спасти меня и т. д.).

Такие условия могут вслух проговариваться субъектом оборотничества и быть известными слушателям с самого начала сказки (I weird ye to be a Laidly Worm, / And borrowed shall ye never be, / Until Childe Wynd, the King's own son / Come to the Heugh and thrice kiss thee; / Until the world comes to an end, / Borrowed shall ye never be / Быть тебе Уродливым Змеем, пока Чайлд Уинд не придет не поцелует тебя трижды, до тех пор, пока существует мир, ты будешь внушать отвращение). Однако в большинстве случаев эти условия раскрываются в финальной части сказки, после того как герой освобождается от колдовских чар. В таком случае объект оборотничества является в сказке носителем знания о необходимых условиях снятия заклятия, но далеко не всегда может передать их герою профанного мира, которому предстоит быть субъектом в ситуации расколдовывания. В таком случае последний действует неосознанно, интуитивно или подчиняется давлению со стороны его окружения.

Установление контакта с персонажем, подвергшимся колдовству, позволяет героине как потенциальному субъекту оборотничества получить все необходимые инструкции, имеющие целью освободить пострадавшую сторону от действия колдовских чар. Яркий пример такого инструктажа мы находит в сказке «Tamlane»:

You must spring upon me suddenly, and I will fall to the ground. Then seize me quick, and whatever change befall me, for they will exercise all their magic on me, cling hold to me till they turn me into red-hot iron. Then cast me into this pool and I will be turned back into a mother-naked man. Cast then your green mantle over me, and I shall be yours, and be of the world again (Jacobs, 1894) / Тебе нужно внезапно прыгнуть на меня, и я упаду на землю. Тогда крепко хватай меня, и, что бы ни случилось, а они применят всю свою магию, крепко держи меня, пока меня не превратят в раскаленное железо. Тогда бросай меня в воду, и я снова стану человеком. Тогда набрось на меня свою зеленую мантию, и я стану твоим и буду принадлежать миру. 
В нужное время героиня поступает именно таким образом, который ей был открыт, и процесс оборотничества запускается:

...Springing forward she seized the bridle of the milk-white steed and pulled its rider down. And as soon as he had touched the ground she let go the bridle and seized him in her arms (Jacobs, 1894) / ...Прыгнув вперед, она схватила под уздцы молочно-белого жеребца и стащила всадника вниз. Как только он коснулся земли, она отпустила уздечку и схватила его.

Исследование лингвосемиотических средств реализации концепта «оборотничество» свидетельствует о том, что данный концепт в своей полной форме может проявляться в пределах одного сказочного текста более одного раза. Все элементы структурносодержательного минимума остаются постоянными; переменной величиной становится лишь интенция субъекта оборотничества, в соответствии с которой речь идет о наложении заклятия (заколдовывание), снятии заклятия (расколдовывание) и каре за содеянное зло (оборотничество как воздаяние). Дискурсивная сцепка двух мотивов оборотничества (заколдовывание - расколдовывание) происходит за счет вербализации когнитивного признака «условия возвращения исходного облика».

\section{Факультативные классификаторы} концепта «shape shifting / оборотничество»

Факультивными классификаторами концепта, не входящими в его структурносодержательный минимум и имеющими в англоязычном сказочном дискурсе нерегулярную лингвосемиотическую актуализацию, являются «продолжительность действия заклятия» (темпоральный), «каузальный», «состояние объекта оборотничества» и «последствия оборотничества».

Продолжительность действия заклятия. По сравнению с остальными факультативными классификаторами темпоральный имеет наиболее детальную репрезентацию в сказочном дискурсе: активно используются нумерологические и хронологические маркеры, в том числе указатели неопределенной (реже определенной) длитель- ности (a dove by day; at night her spells lose their power; By day a bird, by night a prince; you have broken the enchantment by night; that by day has yet to be overcome; twelve long years have I waited for a deliverer; Molly was to go lame on her right leg for seven long years; lame she went for nearly the whole of that period; lameness seized him all on one side, which continued on him as long as he lived; the pixies were kind enough to let her off with a lame leg, which was so to continue only for seven years / голубь днем; ночью ее заклинания теряют силу; днем - птица, ночью - принц; ты разрушила ночные чары; ночные чары еще предстоит снять; долгие двенадцать лет я ждала посланника; Молли должна была хромать на правую ногу семь долгих лет; она охромела почти на все это время; хромота осталась с ним до конца его дней; пикси проявили доброту, освободив ее от хромоты, которая продолжалась семь лет).

Каузальный классификатор характеризуется слабой дискурсивной манифестацией, в которой эксплицитное выражение (например, wanted to marry him / хотела выйти за него замуж) чаще заменяется имплицитным, понимаемым только при учете контекста. Так, колдовские действия мачехи-ведьмы в сказке «The Laidly Worm of Spindleston Heugh» обусловлены исключительно ее завистью к красоте и молодости падчерицы. В сказке прямая номинация эмоционального состояния королевы как субъекта оборотничества подменяется указанием на ее интенцию:

I'll soon put an end to her beauty (Jacobs, 1890) / Я скоро положу конец ее красоте.

Состояние объекта оборотничества как классификатор соответствующего концепта представлено единичными вербальными маркерами (например, live pitiably in confinement / влачить жалкое существование в заточении), что подчеркивает бо́льшую ориентацию сказки на действие, чем на воссоздание эмоциональных состояний и переживаний героев.

Последствия оборотничества. Воздаяние за насильственное оборотничество получает эксплицитную вербализацию в исклю- 
чительно редких случаях (например, be rightly punished / получить по заслугам). Гораздо чаще субъект оборотничества лишается жизни без прямой референции к тому, что было им содеяно, либо в силу своей обезличенности и удаленности ситуации наложения чар во времени остается безнаказанным.

\section{Выводы}

Концепт «shape shifting / оборотничество» в английской традиционной культуре имеет вид сценарного фрейма, в структурный минимум которого входят классификаторы «субъект оборотничества», «объект оборотничества», «действие» и «обстоятельства действия». К факультативным классификаторам концепта, имеющим в англоязычном сказочном дискурсе крайне нерегулярную лингвосемиотическую актуализацию, относятся «темпоральный», «каузальный», «состояние объекта оборотничества» и «последствия оборотничества».

Связь концепта «shape shifting / оборотничество» в национальной концептосфере с другими концептами группы «изменение внешнего облика» осуществляется за счет когнитивных признаков «увечья» и «внешнее уподобление тотему», которые принадлежат классификатору «объект оборотничества» и относятся к периферийной области концепта.

Лингвосемиотическая манифестация концепта чрезвычайно разнообразна и представлена широкой номенклатурой единиц 30оморфного, орнитоморфного, амфибиоморфного, рептилеморфного, инсектоморфного, соматического, артефактного, минерального, колороморфного, темпорального, нумерологического, эзотерического, манипулятивного, акционального и других кодов. Противопоставление исходного и трансформированного обликов объектов оборотничества реализуется в англоязычном сказочном дискурсе в оппозициях «живой - мертвый», «прекрасное - безобразное», «возвышенное - ужасное».

В своей полной форме концепт «shape shifting / оборотничество» может проявляться в пределах одного сказочного текста более одного раза. Все элементы структурносодержательного минимума остаются постоянными; переменной величиной становится лишь интенция субъекта оборотничества, в соответствии с которой возможно наложение заклятия (заколдовывание), снятие заклятия (расколдовывание) и кара за содеянное зло (оборотничество как воздаяние). Дискурсивная связь двух мотивов оборотничества (заколдовывание - расколдовывание) происходит за счет вербализации когнитивного признака «условия возвращения исходного облика».

\section{СПИСОК ЛИТЕРАТУРЫ}

Астафурова Т. Н., Плахова О. А., 2013. Лингвосемиотика магии в сказочном дискурсе // Вестник Волгоградского государственного университета. Серия 2, Языкознание. № 3 (19). C. 119-127.

Жарова О. С., 2014. Образ волка как идея реализации жизненных аспектов бытия у народов Евразии // Сборники конференций НИЦ Социосфера. № 22. С. 92-96.

Калинин С. С., 2015. Образ-символ кошки в мифологической картине мира древних германцев

// Социокультурное пространство России и зарубежья: общество, образование, язык. № 4. C. $92-100$.

Киндря Н. А., 2009. Оборотничество и оборачивание в мифопоэтической картине мира // Ученые записки Российского государственного социального университета. № 3. С. 173-176.

Киндря Н. А., 2010. Животные-тотемы в древнем сознании: лингвосемиотический контекст // Ученые записки Российского государственного социального университета. № 1. С. 136-140.

Коломакина Б. А., 2012. Мотив превращения человека в животное в волшебных сказках бурят и шорцев // Сибирский филологический журнал. № 3. С. 19-23.

Коломакина Б. А., 2017. Мотив превращения в сибирских сказаниях: структура, классификация // Филологические науки. Вопросы теории и практики. № 7 (73), ч. 1. С. 34- 44.

Королькова Я. В., 2013. Культурная модель оборотничества в романе-фэнтези М. Семеновой о Волкодаве // Филологические науки. Вопросы теории и практики. № 11, ч. 1. С. 87-89.

Краюшкина Т. В., 2008. Группа мотивов изменения внешнего облика человека в русской народной волшебной сказке: типы и функции // Вестник Челябинского государственного университета. № 12. С. 73-78.

Кузьмин А. А., 2009. Трансформации «телесного кода» в русской традиционной культуре (на материале волшебных сказок) // Вестник Вятского государственного гуманитарного университета. № 4. С. 104-107. 
Любимова Е. А., 2016. Мотив оборотничества в пьесе-сказке Е.Л. Шварца «Обыкновенное чудо» // Актуальные проблемы гуманитарных наук в России и за рубежом. Новосибирск : Инновац. центр развития образования и науки. С. 33-35.

Неклюдов С. Ю., 1979. О кривом оборотне (к исследованию семантики фольклорного мотива) // Проблемы славянской этнографии. Л. : Наука. С. 133-141.

Неклюдов С. Ю., 1998. Образы потустороннего мира в народных верованиях и традиционной словесности // Восточная демонология. От народных верований к литературе. М. : Наследие. С. 6-43.

Плахова О. А., 2011а. Динамика мифологического концепта «Великан» (на материале английских народных сказок) // Вестник Пермского университета. Российская и зарубежная филология. № 2 (14). С. 95-100.

Плахова О. А., 2011б. Медиаторная роль мифоконцепта «Мальчик-с-пальчик / Tom Thumb» в английской национальной концептосфере // Beстник Московского государственного гуманитарного университета им. М.А. Шолохова. Филологические науки. № 2. С. 79-86.

Плахова О. А., 2011в. Мифологическое и социальное в образе Тома Хикатрифта: описание макроструктуры концепта // Вестник Иркутского государственного лингвистического университета. № 4. С. 52-60.

Плахова О. А., 2012. Манифестация представлений о фейри как носителях магического знания в англоязычном сказочном дискурсе // Вестник Тихоокеанского государственного университета. № 3. С. 239-248.

Плахова О. А., 2013. Лингвосемиотика английской сказки: жанровое пространство, знаковая репрезентация, дискурсивная актуализация : дис. ... д-ра филол. наук. Волгоград. 542 с.

Плахова О. А., Астафурова Т. Н., 2011. Демифологизация концепта «fairy» в англоязычном сказочном дискурсе // Вестник Волгоградского государственного университета. Серия 2, Языкознание. № 2 (14). С. 84-90.

Решетникова А. П., 2006. Образ животного-первопредка - иносказательный маркер «чужого» // Наука и образование. № 3. С. 120-126.

Тиманова О. И., 2008. Мифопоэтические контексты «волшебной повести» Антония Погорельского «Черная курица, или Подземные жители» // Вестник Ленинградского государственногоуниверситета им. А.С. Пушкина. № 4 (16). С. 19-27.

Хазанкович Ю. Г., 2009. Образ «волка» в фольклоре и литературе: к проблеме архетипа // Известия Санкт-Петербургского государственного экономического университета. № 2. С. 186-188.

\section{ИСТОЧНИКИ И СЛОВАРИ}

Jacobs J. English Fairy Tales. L. : David Nutt, 1890. URL: www.sacred-texts.com/neu/eng/eft/ index.htm (date of access: 29.01.2020).

Jacobs J. More English Fairy Tales. L. : David Nutt, 1894. URL: https://www.sacred-texts.com/neu/ eng/meft/index.htm (date of access: 29.01.2020).

Keding D., Douglas A. English Folktales. Westport, L. : Greenwood Publishing Inc., 2005. 231 p.

LDELC - Longman Dictionary of English Language and Culture. Harlow (Essex) : Longman Group UK Ltd., 2000. 1568 p.

\section{REFERENCES}

Astafurova T.N., Plakhova O.A., 2013. Lingvosemiotika magii $v$ skazochnom diskurse [Linguosemiotics of Magic in Folk Tale Discourse]. Vestnik Volgogradskogo gosudarstvennogo universiteta. Seriya 2, Yazykoznanie [Science Journal of Volgograd State University. Linguistics], no. 3 (19), p. $119-127$

Zharova O.S., 2014. Obraz volka kak ideya realizatsii zhiznennykh aspektov bytiya u narodov Evrazii [The Image of a Wolf As an Idea of Realization of the Vital Aspects of Existence Among the Peoples of Eurasia]. Sborniki konferentsiy NITS Sotsiosfera [Proceedings of the Research Centre Sociosfera Conferences], no. 22, pp. 92-96.

Kalinin S.S., 2015. Obraz-simvol koshki v mifologicheskoy kartine mira drevnikh germantsev [Use of Cat As an Image and Symbol in the Mythological World View of Ancient Germanic People]. Sotsiokulturnoe prostranstvo Rossii i zarubezhya: obshchestvo, obrazovanie, yazyk, no. 4, pp. 92-100.

Kindrya N.A., 2009. Oborotnichestvo i oborachivanie v mifopoeticheskoy kartine mira [Transmogrification and Wrap in Myth's and Poetic Picture of the World]. Uchenye zapiski Rossiyskogo gosudarstvennogo sotsialnogo universiteta, no. 3,pp. 173-176.

Kindrya N.A., 2010. Zhivotnye-totemy v drevnem soznanii: lingvosemioticheskiy kontekst [Animal Totems in Ancient Consciousness: Linguosemiotic Context]. Uchenye zapiski Rossiyskogo gosudarstvennogo sotsialnogo universiteta, no. 1 , pp. 136-140.

Kolomakina B.A., 2012. Motiv prevrashcheniya cheloveka $\mathrm{v}$ zhivotnoe $\mathrm{v}$ volshebnykh skazkakh buryat i shortsev [The Motif of Transfiguring a Human Being into an Animal 
in Buryat and Shor Fairy Tales]. Sibirskiy filologicheskiy zhurnal [Siberian Journal of Philology], no. 3, pp. 19-23.

Kolomakina B.A., 2017. Motiv prevrashcheniya v sibirskikh skazaniyakh: struktura, klassifikatsiya [The Motif of Transformation in Siberian Legends: Structure and Classification]. Filologicheskie nauki. Voprosy teorii i praktiki [Philology. Theory \& Practice], no. 7 (73), part 1, pp. 34-44.

Korolkova Ya.V., 2013. Kul'turnaya model' oborotnichestva $v$ romane-fentezi M. Semenovoy o Volkodave [Cultural Model of Lycanthropy in Fantasy Novels About Wolfhound by M. Semenova]. Filologicheskie nauki. Voprosy teorii i praktiki [Philology. Theory \& Practice], no. 11, part 1, pp. 87-89.

Krayushkina T.V., 2008. Gruppa motivov izmeneniya vneshnego oblika cheloveka v russkoy narodnoy volshebnoy skazke: tipy i funktsii [A Group of Motives for Changing the Appearance of a Person in a Russian Folk Fairy Tale: Types and Functions]. Vestnik Chelyabinskogo gosudarstvennogo universiteta [Bulletin of Chelyabinsk State University], no. 12, pp. 73-78.

Kuzmin A.A., 2009. Transformatsii «telesnogo koda» $\mathrm{v}$ russkoy traditsionnoy kul'ture (na materiale volshebnykh skazok) [Transformations of the "Body Code" in Russian Traditional Culture (On the Material of Fairy Tales)]. Vestnik Vyatskogo gosudarstvennogo gumanitarnogo universiteta [Herald of Vyatka State University], no. 4, pp. 104-107.

Lyubimova E.A., 2016. Motiv oborotnichestva v p'eseskazke E.L. Shvartsa «Obyknovennoe chudo» [The Motif of Werewolf in the Fairy Tale Play by E.L. Schwartz "An Ordinary Miracle"]. Aktualnye problemy gumanitarnykh nauk $v$ Rossii $i$ za rubezhom [Actual Problems of the Humanities in Russia and Abroad]. Novosibirsk, Innovatsionnyy tsentr razvitiya obrazovaniya $\mathrm{i}$ nauki, pp. 33-35.

Neklyudov S.Yu., 1979. O krivom oborotne ( $\mathrm{k}$ issledovaniyu semantiki folklornogo motiva) [About the Crooked Werewolf (To the Study of the Semantics of the Folklore Motif)]. Problemy slavyanskoy etnografii [Problems of Slavic Ethnography]. Leningrad, Nauka Publ., pp. 133-141.

Neklyudov S.Yu., 1998. Obrazy potustoronnego mira v narodnykh verovaniyakh i tradicionnoy slovesnosti [Images of the Other World in Folk Beliefs and Traditional Literature]. Vostochnaya demonologiya. Ot narodnykh verovaniy $k$ literature [Eastern Demonology. From Folk
Beliefs to Literature]. Moscow, Nasledie Publ., pp. 6-43.

Plakhova O.A., 2011a. Dinamika mifologicheskogo kontsepta «Velikan» (na materiale angliyskikh narodnykh skazok) [Dynamics of the Mythological Concept "Giant” (On English Folk Tales)]. Vestnik Permskogo universiteta. Rossiyskaya i zarubezhnaya filologiya [Perm University Herald. Russian and Foreign Philology], no. 2 (14), pp. 95-100.

Plakhova O.A., 2011b. Mediatornaya rol' mifokontsepta «Malchik-s-palchik / Tom Thumb» v angliyskoy natsionalnoy kontseptosfere [The Mediatory Role of the Mythoconcept "Tom Thumb" in the English National Conceptosphere]. Vestnik Moskovskogo gosudarstvennogo gumanitarnogo universiteta im. M.A. Sholokhova. Filologicheskie nauki, no. 2, pp. 79-86.

Plakhova O. A., 2011v. Mifologicheskoe i socialnoe v obraze Toma Khikatrifta: opisanie makrostruktury kontsepta [Mythological and Social Features of Tom Hickathrift's Image: Towards the Macrostructure of the Concept]. Vestnik Irkutskogo gosudarstvennogo lingvisticheskogo universiteta, no. 4, pp. 52-60.

Plakhova O.A., 2012. Manifestatsiya predstavleniy o feyri kak nositelyakh magicheskogo znaniya $\mathrm{v}$ angloyazychnom skazochnom diskurse [Manifestation of Ideas of Fairies As Magic Knowledge Bearers in the English Folk Tale Discourse]. Vestnik Tikhookeanskogo gosudarstvennogo universiteta, no. 3 , pp. 239-248.

Plakhova O.A., 2013. Lingvosemiotika angliyskoy skazki: zhanrovoe prostranstvo, znakovaya reprezentatsiya, diskursivnaya aktualizatsiya: dis. ... d-ra filol. nauk [Linguosemiotics of the English Fairy Tale: Genre Space, Symbolic Representation, Discursive Actualization. Dr. philol. sci. diss.]. Volgograd. 542 p.

Plakhova O.A., Astafurova T.N., 2011. Demifologizatsiya kontsepta «fairy» v angloyazychnom skazochnom diskurse [Demythologization of the Concept "Fairy" in English Folk Tale Discourse]. Vestnik Volgogradskogo gosudarstvennogo universiteta. Seriya 2, Yazykoznanie [Science Journal of Volgograd State University. Linguistics], no. 2 (14), pp. 84-90.

Reshetnikova A.P., 2006. Obraz zhivotnogopervopredka - inoskazatelnyy marker «chuzhogo» [The Image of the Ancestral Animal is an Allegorical Marker of the "Alien"]. Nauka i obrazovanie, no. 3, pp. 120-126.

Timanova O.I., 2008. Mifopoeticheskie konteksty «volshebnoy povesti» Antoniya Pogorelskogo 


\section{МЕЖКУЛЬТУРНАЯ КОММУНИКАЦИЯ}

«Chernaya kuritsa, ili Podzemnye zhiteli» [Mythopoetic Contexts of Antony Pogorelsky's "The Black Hen, or the Underground Inhabitants"]. Vestnik Leningradskogo gosudarstvennogo universiteta im. A.S. Pushkina [Pushkin Leningrad State University Jornal], no. 4 (16), pp. 19-27.

Hazankovich Yu.G., 2009. Demifologizatsiya kontsepta «fairy» v angloyazychnom skazochnom diskurse [Image of Wolf in Folklore and Literature: To an Archetype Problem]. Izvestiya Sankt-Peterburgskogo gosudarstvennogo ekonomicheskogo universiteta, no. 2, pp. 186-188.

\section{SOURCES AND DICTIONARIES}

Jacobs J. English Fairy Tales. London, David Nutt, 1890. URL: www.sacred-texts.com/neu/eng/eft/ index.htm (accessed 29 January 2020).

Jacobs J. More English Fairy Tales. London, David Nutt, 1894. URL: www.sacred-texts.com/neu/ eng/meft/index.htm (accessed 29 January 2020).

Keding D., Douglas A. English Folktales. Westport, London, Greenwood Publishing Inc., 2005. 231 p.

Longman Dictionary of English Language and Culture. Harlow (Essex), Longman Group UK Ltd., 2000. 1568 p.

\section{Information About the Author}

Olga A. Plakhova, Doctor of Sciences (Philology), Associate Professor, Professor, Department of Theory and Methods of Teaching Foreign Languages and Cultures, Togliatti State University, Belorusskaya St, 14, 445020 Togliatti, Russia, plahova_oa@mail.ru, https://orcid.org/0000-0003-0911-2546

\section{Информация об авторе}

Ольга Александровна Плахова, доктор филологических наук, доцент, профессор кафедры теории и методики преподавания иностранных языков и культур, Тольяттинский государственный университет, ул. Белорусская, 14, 445020 г. Тольятти, Россия, plahova_oa@mail.ru, https://orcid.org/0000-0003-0911-2546 